\title{
HIV ile Enfekte Hastalarda Latent Tüberküloz Enfeksiyonunu (LTBE) Belirlemede Tüberkülin Deri Testi (TDT) ve T-SPOT.TB Testlerinin Karşılaştırılması
}

\author{
Comparison of Tuberculin Skin Test (TST) and T-SPOT.TB \\ Tests for Diagnosis of Latent Tuberculosis Infection (LTBI) \\ in HIV-infected Patients
}

\author{
Umut Devrim BINAY ${ }^{1}$, Muzaffer FiNCANCl ${ }^{2}$, Esra FERSAN ${ }^{3}$, Faruk KARAKEÇiLi ${ }^{4}$ \\ ${ }^{1}$ Erzincan Mengücek Gazi Eğitim ve Araştırma Hastanesi, Enfeksiyon Hastalıkları ve Klinik Mikrobiyoloji Kliniği, Erzincan. \\ ${ }^{1}$ Erzincan Mengucek Gazi Training and Research Hospital, Department of Infectious Diseases and Clinical Microbiology, \\ Erzincan, Turkey. \\ 2 İstanbul Eğitim ve Araştırma Hastanesi, Enfeksiyon Hastalıkları ve Klinik Mikrobiyoloji Kliniği, İstanbul. \\ 2 istanbul Training and Research Hospital, Department of Infectious Diseases and Clinical Microbiology, Istanbul, Turkey. \\ ${ }^{3}$ Kanuni Sultan Süleyman Eğitim ve Araştırma Hastanesi, Enfeksiyon Hastalıkları ve Klinik Mikrobiyoloji Kliniği, İstanbul. \\ ${ }^{3}$ Kanuni Sultan Süleyman Training and Research Hospital, Department of Infectious Diseases and Clinical Microbiology, \\ istanbul, Turkey. \\ ${ }^{4}$ Erzincan Binali Yıldırım Üniversitesi Tıp Fakültesi, Enfeksiyon Hastalıkları ve Klinik Mikrobiyoloji Anabilim Dalı, Erzincan. \\ ${ }^{4}$ Erzincan Binali Yıldırım University Faculty of Medicine, Department of Infectious Diseases and Clinical Microbiology, \\ Erzincan, Turkey.
}

Makale Atıfı: Binay UD, Fincancı M, Fersan E, Karakeçili F. HIV ile enfekte hastalarda latent tüberküloz enfeksiyonunu (LTBE) belirlemede tüberkülin deri testi (TDT) ve T-SPOT.TB testlerinin karşılaştırılması. Mikrobiyol Bul 2019;53(4):388-400.

\section{ÖZ}

Mycobacterium tuberculosis, insan immün yetmezlik virüsü (HIV) ile enfekte hastalarda en sık görülen fırsatçı enfeksiyon etkenidir. Aktif tüberküloz (TB) hastalığı gelişmesini önlemede en önemli basamak, latent TB enfeksiyonunun (LTBE) tanınması ve tedavi edilmesidir. Ülkemizdeki TB insidansı, yüzbinde 15.4 olup HIV ile enfekte hastaların LTBE açısından mutlaka araştıııması gerekmektedir. LTBE tanısında, tüberkülin deri testi (TDT) ve interferon-gama salınım testleri (IGST) kullanılmakta olup standart bir yöntem yoktur. Bu çalışmada HIV ile enfekte hastalarda, LTBE'nin tanısında TDT ve IGST testlerinden biri olan T-SPOT.TB testlerinin karşılaştırılması amaçlanmıştır. Daha önce aktif TB enfeksiyonu geçirmemiş, LTBE nedeniyle tedavi almamış ve başvuru anında aktif TB enfeksiyonu olmayan hastalar çalışmaya dahil edilmiştir. Haziran 2015-Mart 2016 tarihleri arasında Enfeksiyon Hastalıkları ve Klinik Mikrobiyoloji Polikliniğine başvuran 100 HIV ile enfekte hasta, kesitsel olarak değerlendirilmiştir. Çalışmaya dahil edilen hastaların son bir ay içerisindeki CD4+ T lenfosit sayıları incelenmiş ve tüm hastalara başvuru anında akciğer grafisi çekilmiştir. Çalışmaya alınan hastalar son bir ay içerisinde TDT yapılmamış, klinik ve laboratuvar bulguları ile aktif TB enfeksiyonu dışlanan hastalardır. Hastalardan başvuru anında, T-SPOT.TB testi için kan örneği alındıktan sonra TDT yapılmıştır. Çalışmamıza katılan hastaların \%87'si erkek ve yaş ortalamaları 40.2 
bulunmuştur. Ortalama CD4+ T lenfosit sayısı 605 (aralık: 26-1313) hücre/mm³ olarak bulunmuştur. Olguların \%16'sı TB hastasıyla karşılaşmış ve \%81 hastada Bacillus Calmette Guerin (BCG) aşı skarı tespit edilmiştir. TDT pozitifliği \%22.9, T-SPOT.TB test pozitifliği \%22 oranında saptanırken iki test arasındaki uyum, orta düzeyde bulunmuştur $(K a p p a=0.491)$. Hastaların BCG aşısı olmalarının ve TB hastasıyla karşılaşmış olmalarının, TDT ve T-SPOT.TB test pozitifliğini etkilemediği tespit edilmiştir ( $p>0.05)$. Hastaların CD4+ T lenfosit sayısı ve TDT ölçüm değeri arasında pozitif korelasyon saptanmıştır $(r=0.3, p=0.003)$. Buna göre CD4+ T lenfosit sayısı arttıkça, TDT pozitifliğinin arttığı izlenmiştir $(p=0.007)$. T-SPOT.TB testinin, CD4+ T lenfosit sayısından etkilenmediği görülmüştür $(p=0.289)$. Çalışmamız, TDT'nin CD4+ T lenfosit sayısından etkilendiğini ve TDT'ye hasta uyumunun güç olduğunu göstermiştir. Buna karşın, T-SPOT.TB testinin CD4+ T lenfosit sayısından etkilenmediği tespit edilmiştir. T-SPOT.TB test pozitifliği ile CD4+ T lenfosit sayısı arasında istatistiksel olarak anlamlı bir fark saptanmamıştır $(p=0.289)$. Her iki test arasındaki uyum orta düzeyde bulunmuştur. Testler arasındaki uyumsuzluğun, TDT'nin yalancı negatif veya yalancı pozitif sonuçlarından kaynaklandığı düşünülmüştür. Sonuç olarak, HIV ile enfekte kişilerde, LTBE tanısında T-SPOT.TB testi daha güvenilir bulunmuştur. Bu bulgular ışı̆̆ında, özellikle CD4+ T lenfosit sayısı düşük olan HIV ile enfekte hastalarda, LTBE tanısının konulabilmesi için, öncelikle T-SPOT.TB testinin tercih edilmesi gerektiği düşünülmüştür.

Anahtar kelimeler: HIV; latent tüberküloz enfeksiyonu; TDT; ICST.

\section{ABSTRACT}

Tuberculosis (TB) is the most common opportunistic infection in human immunodeficiency virus (HIV)-infected patients. Diagnosis and treatment of latent tuberculosis infection (LTBI) is the most important step in preventing the development of active TB. In our country where TB is moderately endemic, HIV-infected patients should be investigated for LTBI. Tuberculin skin test (TST) and interferongamma release assays (IGRA) are used in the diagnosis of LTBI but there isn't a standard practice. The aim of this study is to compare the TST and T-SPOT.TB test efficiency in the diagnosis of LTBI in HIVinfected patients. Patients who had no previous active TB infection, who were not treated for LTBI and who had no active tuberculosis infection at the time of admission were included in the study. A total of 100 HIV-infected patients who were admitted to the Infectious Diseases and Clinical Microbiology outpatient clinic between June 2015 and March 2016 were evaluated cross-sectionally. CD4+ T lymphocyte counts in the last one month were detected. All patients underwent chest radiography at the time of admission. Patients who are not considered as active TB infection with clinical and laboratory findings and who had no TST within the last one month were included in the study. TST was performed after the blood samples were taken for T-SPOT.TB test. In our study, $87 \%$ of the patients were male and the mean age was 40.2 . The mean CD4+ T lymphocyte count was 605 cells $/ \mathrm{mm}^{3}$ (26-1313). $16 \%$ of the patients had a history of encountring a person with tuberculosis and $81 \%$ had BCG vaccination scar. TST positivity and T-SPOT.TB positivity were $22.9 \%$ and $22 \%$, respectively. The concordance between the two tests was found to be moderate $(K a p p a=0.491)$. It was determined that $B C G$ vaccination and the presence of a contact with a patient with TB did not affect TST and T-SPOT.TB test positivity $(p>0.05)$. There was a positive correlation between CD4+ T lymphocyte count and TST measurement values $(r=$ $0.3, p=0.003$ ). Accordingly, as the number of CD4+ T lymphocytes increased, TST positivity increased $(p=0.007)$. T-SPOT.TB test was not affected by CD4+ T lymphocyte count $(p=0.289)$. Our study showed that TST was affected by CD4+ T lymphocyte count and patients' compliance with this test was also low. On the contrary T-SPOT.TB test was not affected by CD4+ T lymphocyte count. There was no statistically significant difference between T-SPOT.TB test positivity and CD4+ T lymphocyte count ( $p=$ 0.289). The concordance between the two tests was found to be moderate. It is thought that the main reason for the discordance between the tests is due to false negative or false positive results of TST. In conclusion, T-SPOT.TB was found more reliable in the diagnosis of LTBI in HIV-infected individuals. In the light of these findings, especially in HIV-infected patients with low CD4+ T lymphocyte counts, T-SPOT.TB test can be considered for LTBI diagnosis.

Keywords: HIV; latent tuberculosis infection; TST; IGRA. 


\section{Gíriş}

Insan immün yetmezlik virüsü (HIV) ile enfekte hastalarda aktif tüberküloz (TB) enfeksiyonu, önemli bir morbidite ve mortalite nedeni olmaya devam etmektedir. TB, HIV/ AIDS hastalarında halen en sık görülen fırsatçı enfeksiyondur. HIV ile enfekte kişilerde, ölümlerin 1/3'ü TB'ye bağlı olmaktadır ve TB'ye bağlı ölümlerin yaklaşık \%30'u HIV ile enfektedir ${ }^{1,2}$.

HIV serokonversiyonu geliştikten sonraki ilk yıl içerisinde, aktif TB enfeksiyonu gelişme olasııı̆ı iki kat artmaktadır. Bu durum HIV serokonversiyonu sonrası CD4+ T lenfosit sayısındaki düşüşle açıklanmaktadır. HIV ile enfekte kişilerde, aktif TB enfeksiyonu gelişme riski ise 20-37 kat artmaktadır. Bununla birlikte, her yıl yaklaşık \%10 oranında latent TB reaktivasyon riski vardır ki bu oran sağlıkı bireylerde hayat boyu \%5-10 arasındadır ${ }^{3}$.

Aktif TB enfeksiyonu gelişmesini önlemede en önemli basamak latent TB enfeksiyonunun (LTBE) tanınması ve tedavi edilmesidir, ${ }^{1,4-6}$. Ülkemizdeki TB insidansı, yüzbinde 15.4 olup LTBE varlı̆ı̆, HIV ile enfekte hasta grubunda mutlaka araştırılmalıdır?

LTBE tanısında, altın standart bir test yoktur. Uzun yıllardır kullanılan tüberkülin deri testi (TDT), "Bacillus Calmette Guerin (BCG)" aşısı yapılmış olan ve TB dışı mikobakteriler ile enfekte hasta grubunda yalancı pozitif olabilir. Ayrıca, hastanın iki kez testin uygulanması ve okunması amacıyla hastaneyi ziyaret etmesini gerektirmektedir. Ciddi immünsupresif hasta gruplarında negatif sonuçlar vermesi, TDT'nin bir diğer dezavantajıdır ${ }^{4,6,8,9}$. Daha yeni testlerden olan interferon-gama (IFN- $\gamma$ ) salınım testlerinin (IGST) ise BCG aşısı ve TB dışı mikobakteri enfeksiyonlarından etkilendiği bildirilmemiştir. Ancak, bu testlerin de yüksek maliyetli olmaları kullanımlarını sınırlamaktadır ${ }^{10-13}$. Yapılan bazı çalışmalarda, IGST testlerinden T-SPOT.TB test, Quantiferon testine göre daha duyarlı bulunmuştur ${ }^{14-19}$.

Bu çalışmada, HIV ile enfekte hastalarda, LTBE tanısında TDT ile IGST testlerinden biri olan T-SPOT.TB testinin karşılaştııııması amaçlanmışır.

\section{GEREÇ ve YÖNTEM}

Bu çalışma, İstanbul Eğitim ve Araştırma Hastanesi Klinik Araştırmalar Etik Kurulunun onayı ile gerçekleştirildi (Tarih: 20/11/2015 ve Karar no: 735). Tüm hastalar "Aydınlatılmış Yazılı Onam Formu" ile bilgilendirildi ve "Rızası Alınmış Hasta Bilgilendirme Formu" kullanılarak rızası alındı.

\section{Hasta Grubu}

Çalışmamıza, T.C. Sağlık Bakanlığı İstanbul Eğitim ve Araştırma Hastanesi, Enfeksiyon Hastalıkları ve Klinik Mikrobiyoloji Polikliniğinde takip edilen, HIV ile enfekte 100 hasta dahil edildi. Ocak 2008-Haziran 2015 tarihleri arasında takip edilen hastaların HIV takip formları taranarak, çalışmaya dahil edilme kriterlerini sağlayan hastalar, antiretroviral tedavi (ART) alıp almama durumuna bakılmaksızın değerlendirildi. Buna göre daha önce TB enfeksiyonu geçirmemiş, LTBE nedeniyle tedavi almamış ve başvuru anında aktif TB 
enfeksiyonu olmayan hastalar çalışmaya dahil edildi. Hastaların demografik verileri (yaş, cinsiyet, geçirilmiş hastalıklar, almakta oldukları tedaviler, takip süreleri vb.), BCG aşısı varlığı, TB olan hasta ile karşılaşma durumu değerlendirildi. Ayrıca hastaların üç aylık aralıklarla CD4+ T lenfosit sayısı, HIV-RNA düzeyi ile detaylı fizik muayene, görüntüleme yöntemleri ve diğer laboratuvar testleri bu formlar üzerinden araştırıldı. HIV-RNA düzeyi için sınır değer 50 kopya/ml olarak kabul edildi. HIV-RNA düzeyi 50 kopya/ml'nin altında olan sonuçlar negatif olarak kabul edildi. Çalışmaya alınan 100 hasta Haziran 2015-Mart 2016 tarihleri arasında LTBE açısından değerlendirildi.

Çalışma grubunu, çalışmaya dahil edilme kriterlerini sağlayan hastalardan, polikliniğe başvuru sırasına göre, çalışmaya dahil olmayı kabul eden hastalar oluşturdu. Çalışmaya dahil edilen hastaların son bir ay içerisindeki CD4+ T lenfosit sayıları tespit edildi. Tüm hastalara, başvuru anında akciğer grafisi çekildi. Son bir ay içerisinde TDT yapılmamış, klinik ve laboratuvar bulguları ile aktif TB enfeksiyonu dışlanan hastalar çalışmaya dahil edildi. Daha önce aktif TB enfeksiyonu veya LTBE nedeniyle tedavi almış hastalar çalışma dışı bırakıldı. Çalışmaya, ART almakta olup HIV-RNA sonucu negatif olan 68 hasta ile ART almayıp HIV-RNA sonucu pozitif olan 32 hasta dahil edildi.

Hastalara başvuru anında LTBE'yi belirlemek amacıyla TDT ve T-SPOT.TB testi yapıldı. T-SPOT.TB testi (Oxford Immunotec, Oxford, İngiltere) için özel tüplere kan örneği alındıktan sonra TDT yapıldı. Alınan kan örneklerine T-Cell Xtend ayracı eklendikten sonra laboratuvara gönderildi. Her iki testin yapılması ve sonuçlarının değerlendirilmesi işlemi alanında deneyimli personel tarafından, rutin işleyiş̧ içinde, kör olarak yapıldı. T-SPOT.TB testi için alınan kandan, santrifüjle mononükleer hücreler elde edildi. Elde edilen mononükleer hücreler, daha önceden IFN- $\gamma$ antikorlarıyla kaplanmış olan kuyucuklara eklendi. Daha sonra bu kuyucuklara TB antijenlerinden ESAT-6 ve CFP-10; pozitif kontrol için de fitohemaglütinin eklendi. Negatif kontrol, antijen içermeyen kuyucuk olarak belirlendi. Bu kuyucuklar bir gece boyunca $37^{\circ} \mathrm{C}^{\prime}$ de $\% 5 \mathrm{CO}_{2}^{\prime}$ li ortamda inkübe edildi. İnkübasyon sonrası kuyucuklar yıkandı ve IFN- $\gamma$ yanıtını ölçebilmek için sekonder konjuge antikorlar eklendi. IFN- $\gamma$ yanıtı gözlenen kuyucuklarda oluşan noktacıklar (spot) otomatik ELISPOT okuyucusu (AID systems, Strassberg, Almanya) tarafından ölçüldü. Test kuyucukları, negatif kontrol kuyucuklarının ortalamasından en az beş tane daha fazla nokta oluşturan hücre içeriyorsa sonuç pozitif olarak kabul edildi ${ }^{20}$.

TDT, hastaların sol ön kolun 2/3 üst iç kısmına, kılsız ve venlerden uzak bir bölgeye, insülin enjektörüyle, $0.1 \mathrm{ml} 5$ TU PPD içeren tüberkülin çözeltisi intradermal olarak uygulandı $^{21}$. Oluşan endurasyonun transvers çapı 48-72 saat sonra mm cinsinden ölçüldü. Endürasyon çapı $5 \mathrm{~mm}$ ve üzeri olan sonuçlar pozitif olarak kabul edildi. TDT sonucu negatif olarak değerlendirilen olgulara iki hafta sonra testin tekrarlanması planlandı.

\section{İstatistiksel Analiz}

İstatistiksel analiz için SPSS (Statistical Package for Social Sciences) 15.0 for Windows programı kullanıldı. Tanımlayıcı istatistikler; kategorik değişkenler için sayı ve yüzde; sayısal değişkenler için ortalama, standart sapma, minimum, maksimum olarak verildi. Kategorik 
değişkenlerin gruplar arasındaki oranı, ki-kare analizi ile test edildi. Koşulların sağlanamadığı durumlarda, Monte Carlo simülasyonu uygulandı. Sayısal değişkenlerin normal dağılım göstermediği durumlarda bağımsız iki grup, Mann-Whitney U test ile karşılaştırıldı. Sayısal değişkenler arası ilişkiler parametrik test koşullarını sağlamadığında, Spearman korelasyon analizi ile incelendi. İstatistiksel alfa anlamlılık seviyesi, $p<0.05$ olarak kabul edildi.

\section{BULGULAR}

Çalışmamıza katılan toplam 100 hastanın 87'si erkek, 13'ü kadın ve yaş ortalamaları 40.2 (19-65) yıl olarak saptanmıştır. CD4+ T lenfosit sayı ortalaması, 605 hücre $/ \mathrm{mm}^{3}$ (26-1313) tespit edilmiştir. ART alan hastaların hepsinin $(n=68)$ HIV-RNA'sı negatifken, almayan hastaların 32'si pozitif bulunmuştur. Hastaların 16'sının TB hastasıyla karşılaşma öyküsü varken, 82'sinin böyle bir öykü vermediği, iki hastanın ise verilerine ulaşılamadığı izlenmiştir. Çalışmaya katılan 81 hastanın BCG aşı skarı varken, 15 hastada BCG skarı izlenmemiştir. TDT ölçümüne gelmediği için dört hastanın verisine ulaşılamamıştır.

Çalışmamıza katılan hastaların TDT ölçüm değerinin ortalaması, 3.6 mm (0-20) olarak saptanmıştır. TDT sonucu 74 (\%77.1) hastanın 5 mm'den küçük; 22 (\%22.9) hastanın ise $5 \mathrm{~mm}$ 'den büyük tespit edilmiştir. TDT ölçümü için dört hasta hastaneye başvurmamıştır. İki hafta sonra booster etki nedeniyle, TDT sonucu negatif olan hastalara tekrar TDT yapılması planlanmış olmasına rağmen bu hastaların hiçbirinin tekrar hastaneye başvuru yapmadığı izlenmiştir. Çalışmamıza katılan hastaların 78'inin T-SPOT.TB testi negatif saptanırken, 22'sinin sonucu pozitif olarak saptanmıştır (Tablo I).

Çalışmamıza katılan 100 hastanın 22'sinde TDT, 22'sinde T-SPOT.TB testi pozitif saptanmıştır. Toplam 13 hastada hem TDT hem de T-SPOT.TB testi pozitif tespit edilmiştir. TDT ile T-SPOT.TB testi arasındaki uyum katsayısı Kappa= 0.491 olarak saptanmıştır. TDT sonucu pozitif saptanan 22 hastanın dokuzunun T-SPOT.TB test sonucu negatif bulunurken, T-SPOT.TB testi pozitif saptanan 21 hastanın sekizinin TDT sonucu negatif olarak belirlenmiştir. TDT ölçümü için gelmeyen dört hasta bu analize dahil edilmemiştir. Dahil edilmeyen dört hastadan birinin T-SPOT.TB test sonucu pozitif olarak saptanmıştır (Tablo II). T-SPOT.TB testi pozitif saptanıp TDT sonucu negatif tespit edilen sekiz hastadan dördünün CD4+ T lenfosit sayısı 500 hücre $/ \mathrm{mm}^{3}$ ün altında tespit edilmiştir.

Aktif TB hastasıyla karşılaşmış olan 16 hastanın altısında TDT ve T-SPOT.TB testleri pozitif, 10'unda negatif bulunmuştur. Aktif TB hastasıyla karşılaşma öyküsü olan dört hastada

\begin{tabular}{|l|cc|}
\hline \multicolumn{2}{|l|}{ Tablo I. Hastaların TDT ve T-SPOT.TB Testlere ilişkin Bulgularının Dağıımı $(n=100)$} \\
\hline TDT* $(\mathrm{mm})$ Ortalama \pm SD (min-maks) $^{*}$ & Negatif & $3.6 \pm 6.0(0-20)$ \\
\hline TDT n (\%) & Pozitif & $74(77.1)$ \\
\cline { 2 - 3 } & Negatif & $22(22.9)$ \\
\hline \multirow{2}{*}{ T-SPOT.TB test n (\%) } & Pozitif & $22(78.0)$ \\
\cline { 2 - 3 } & * Dört hasta tüberkülin deri testi (TDT) ölçümüne gelmemiştir. \\
\hline
\end{tabular}




\begin{tabular}{|c|c|c|c|c|c|}
\hline & & & \multicolumn{2}{|c|}{ T-SPOT.TB Testi } & \multirow[b]{2}{*}{ Toplam } \\
\hline & & & Negatif & Pozitif & \\
\hline \multirow[t]{6}{*}{ TDT } & Negatif & $\mathrm{n}$ & 66 & 8 & 74 \\
\hline & & \% Satır yüzdesi & $\% 89.2$ & $\% 10.8$ & $\% 100$ \\
\hline & & \% Sütun yüzdesi & \%88.0 & $\% 38.1$ & $\% 77.1$ \\
\hline & Pozitif & $\mathrm{n}$ & 9 & 13 & 22 \\
\hline & & \% Satır yüzdesi & $\% 40.9$ & \%59.1 & $\% 100$ \\
\hline & & \% Sütun yüzdesi & $\% 12.0$ & $\% 61.9$ & $\% 22.9$ \\
\hline \multirow[t]{3}{*}{ Toplam } & & $\mathrm{n}$ & 75 & 21 & 96 \\
\hline & & \% Satır yüzdesi & $\% 78.1$ & $\% 21.9$ & $\% 100$ \\
\hline & & \% Sütun yüzdesi & $\% 100$ & $\% 100$ & $\% 100$ \\
\hline
\end{tabular}

hem TDT hem de T-SPOT.TB test pozitif saptanmıştır. Aktif TB hastasıyla karşılaşmış olmak ile TDT ve T-SPOT.TB testi sonuçları arasında ilişki saptanmamıştır ( $p>0.05$ ) (Tablo III).

BCG aşısı olan 81 hastanın 15'inde, olmayan 15 hastanın altısında T-SPOT.TB testi pozitifken; aşılı hastaların 20'sinde ve aşısız hastaların ikisinde TDT pozitif saptanmıştır. İstatistiksel olarak, her iki test arasında BCG aşısı varlığına göre anlamlı fark olmasa da TDT pozitifliği, BCG aşısı olan grupta daha yüksek bulunmuştur ( $p=0.088)$ (Tablo III).

ART almakta olup, HIV-RNA'sı negatif olan 53 hastanın T-SPOT.TB test sonucu negatifken, 15'inin pozitif tespit edilmiştir. HIV-RNA'sı negatif olan hastaların 50'sinde TDT negatifliği mevcutken, 14'ünde TDT pozitifliği belirlenmiştir. ART almadığı için HIV-RNA'sı pozitif olan grupta ise hastaların yedisinin T-SPOT.TB testi pozitifken, 25'inin negatif olduğu saptanmıştır. Aynı grupta sekiz hastada TDT pozitifliği varken, 24 hastada TDT negatif saptanmıştır. HIV-RNA pozitiflik/negatiflik durumuna göre her iki testin pozitiflik oranları arasında istatistiksel olarak anlamlı fark saptanmamıştır ( p>0.05) (Tablo III).

HIV-RNA'sı pozitif ve negatif olan hastaların CD4+ T lenfosit sayı ortalamaları sırasıyla, 572.1 hücre $/ \mathrm{mm}^{3}$ ve 621.6 hücre $/ \mathrm{mm}^{3}$ olarak saptanmıştır. HIV-RNA'sı pozitif ve negatif olan hastaların CD4+ T lenfosit sayı ortalamaları arasında, istatistiksel olarak anlamlı fark saptanmamıştır $(\mathrm{p}=0.958)$ (Tablo IV).

T-SPOT.TB testi pozitif ve negatif olan hastaların CD4+ T lenfosit sayı ortalamaları sırasıyla; 678.9 hücre $/ \mathrm{mm}^{3}$ ve 585.2 hücre $/ \mathrm{mm}^{3}$ olarak saptanmıştır. T-SPOT.TB testi pozitif/negatif sonuçlar ile CD4+ T lenfosit sayı ortalaması olarak arasında istatistiksel olarak anlamlı fark saptanmamıştır ( $\mathrm{p}=0.289)$ (Tablo IV).

TDT pozitif olan hastaların CD4+ T lenfosit sayı ortalaması, 740 hücre $/ \mathrm{mm}^{3}$; negatif olanların ise 558 hücre $/ \mathrm{mm}^{3}$ olarak saptanmıştır. TDT pozitif olan grubun CD4+ T lenfosit sayısı, TDT negatif olan gruba göre istatistiksel olarak anlamlı yüksek bulunmuştur $(p=0.007)$ (Tablo IV). 


\begin{tabular}{|c|c|c|c|c|c|c|}
\hline & & \multicolumn{4}{|c|}{ Aktif TB Hastası ile Karşılaşma } & \multirow[b]{3}{*}{ p } \\
\hline & & \multicolumn{2}{|c|}{ Hayır } & \multicolumn{2}{|c|}{ Evet } & \\
\hline & & $n$ & $\%$ & $n$ & $\%$ & \\
\hline \multirow[t]{2}{*}{ T-SPOT.TB testi } & Negatif & 66 & 80.5 & 10 & 62.5 & 0.186 \\
\hline & Pozitif & 16 & 19.5 & 6 & 37.5 & \\
\hline \multirow[t]{5}{*}{ TDT } & Negatif & 64 & 80.0 & 10 & 62.5 & 0.189 \\
\hline & Pozitif & 16 & 20.0 & 6 & 37.5 & \\
\hline & & \multicolumn{4}{|c|}{ BCG AşıSı } & \\
\hline & & \multicolumn{2}{|c|}{ Yok } & \multicolumn{2}{|c|}{ Var } & \\
\hline & & $\mathbf{n}$ & $\%$ & $\mathbf{n}$ & $\%$ & $p$ \\
\hline \multirow[t]{2}{*}{ T-SPOT.TB testi } & Negatif & 9 & 60.0 & 66 & 81.5 & 0.088 \\
\hline & Pozitif & 6 & 40.0 & 15 & 18.5 & \\
\hline \multirow[t]{5}{*}{ TDT } & Negatif & 13 & 86.7 & 61 & 75.3 & 0.508 \\
\hline & Pozitif & 2 & 13.3 & 20 & 24.7 & \\
\hline & & \multicolumn{4}{|c|}{ HIV-RNA* } & \\
\hline & & \multicolumn{2}{|c|}{ Negatif } & \multicolumn{2}{|c|}{ Pozitif } & \\
\hline & & $\mathrm{n}$ & $\%$ & $n$ & $\%$ & $p$ \\
\hline \multirow[t]{2}{*}{ T-SPOT.TB testi } & Negatif & 53 & 77.9 & 25 & 78.1 & 1.000 \\
\hline & Pozitif & 15 & 22.1 & 7 & 21.9 & \\
\hline \multirow[t]{2}{*}{$\mathrm{TDT}^{* *}$} & Negatif & 50 & 78.1 & 24 & 75.0 & 0.731 \\
\hline & Pozitif & 14 & 21.9 & 8 & 25.0 & \\
\hline
\end{tabular}

TB: Tüberküloz, TDT: Tüberkülin deri testi.

* Antiretroviral tedavi alan bütün hastaların HIV-RNA'sı negatif saptanmıştır.

** Dört hasta TDT ölçümüne gelmediği için bu analize dahil edilmemiştir.

Tablo IV. CD4+ T Lenfosit Sayısına Göre T-SPOT.TB Test, TDT ve HIV-RNA Sonuçlarının Dağılımı

\begin{tabular}{lccc}
\hline & & CD4+ T lenfosit (hücre $/ \mathbf{m m}^{3}$ ) & \\
& & Ortalama \pm SD & 0.289 \\
T-SPOT.TB test & Negatif & $585.2 \pm 26.9$ & \\
\multirow{2}{*}{ TDT } & Pozitif & $678.9 \pm 316.7$ & 0.007 \\
& Negatif & $558.9 \pm 271.8$ & \\
HIV-RNA & Pozitif & $740.0 \pm 257.6$ & 0.958 \\
& Negatif & $621.6 \pm 267.3$ & \\
\hline TDT: Tüberkülin deri testi. & Pozitif & $572.1 \pm 294.8$ & \\
\hline
\end{tabular}


Şekil 1'de TDT pozitif/negatif sonuçların, Şekil 2'de ise T-SPOT.TB pozitif/negatif sonuçların CD4+ T lenfosit sayısına göre dağılımı gösterilmiştir.

Hastaların CD+ T lenfosit sayıları arttıkça, TDT ölçüm değerlerinin de arttığı gözlenmiştir. TDT ölçüm değerinin, CD4+ T lenfosit sayısı ile pozitif yönde, istatistiksel olarak anlamlı ilişkili olduğu saptanmıştır $(r=0.3 ; p=0.003)$. TDT ölçüm değerlerinin CD4+ T lenfosit sayısına göre dağılım grafiği, Şekil 3'te; CD4+ T lenfosit sayısı ile korelasyonu ise Şekil 4 ve Tablo V'te gösterilmiştir.

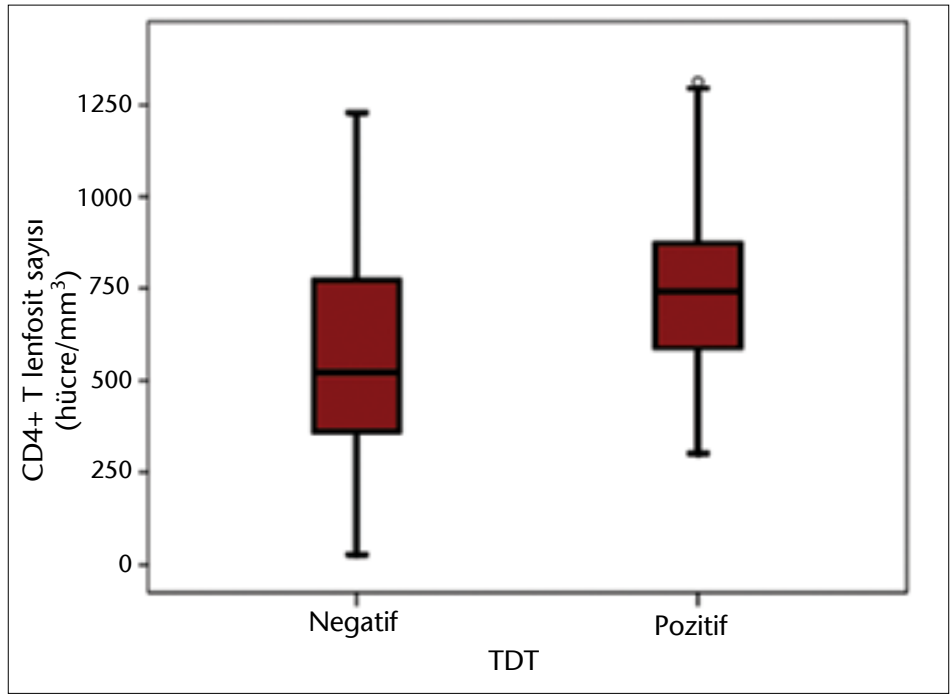

Şekil 1. TDT ve CD4+ T lenfosit sayısı arasındaki ilişki.

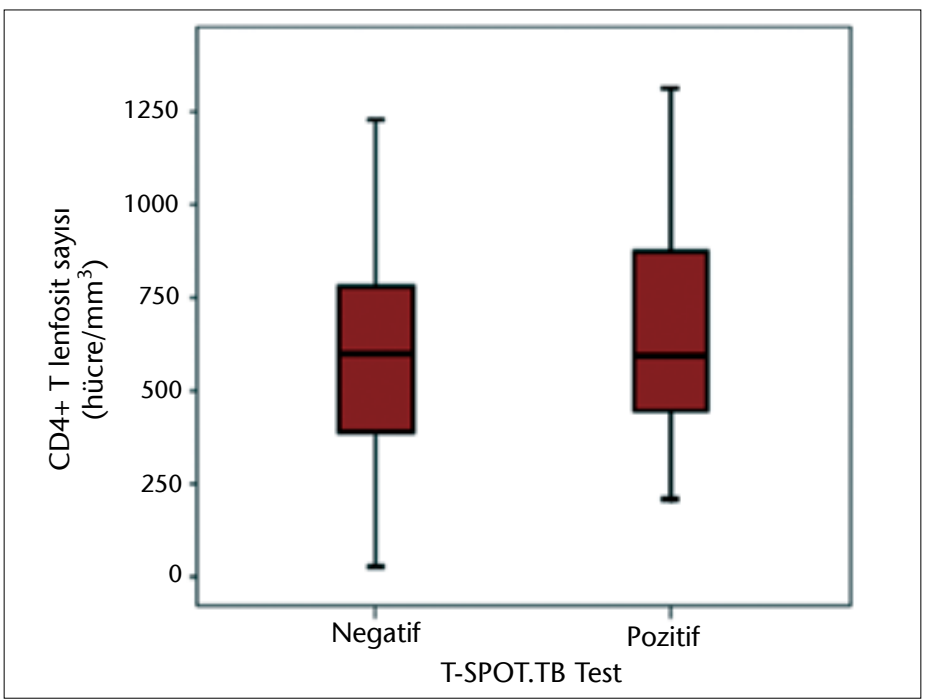

Şekil 2. T-SPOT.TB testi ve CD4+ T lenfosit sayısı arasındaki ilişki. 
HIV ile Enfekte Hastalarda Latent Tüberküloz Enfeksiyonunu (LTBE) Belirlemede Tüberkülin Deri Testi (TDT) ve T-SPOT.TB Testlerinin Karşılaştırılması

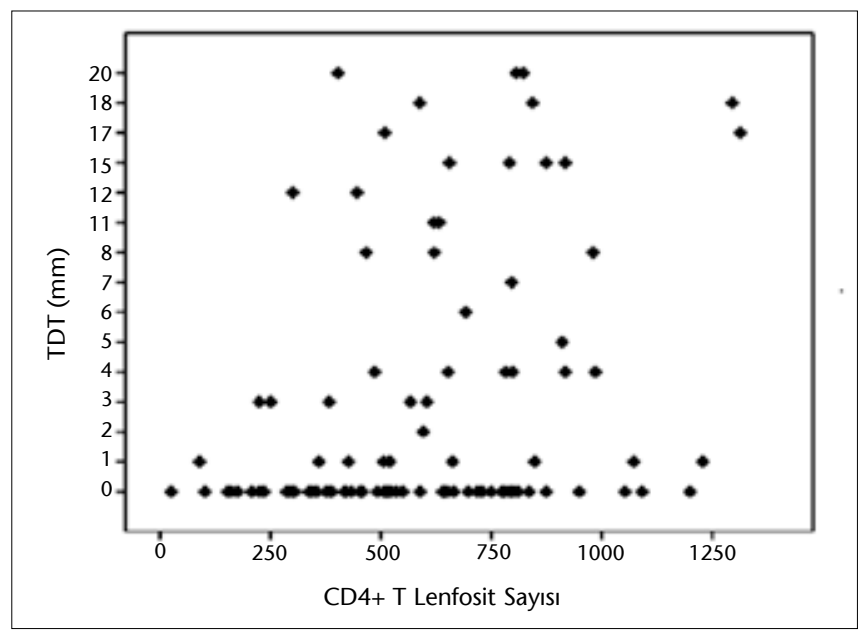

Şekil 3. TDT ölçüm değerlerinin CD4+ T lenfosit sayısına göre dağııımı.

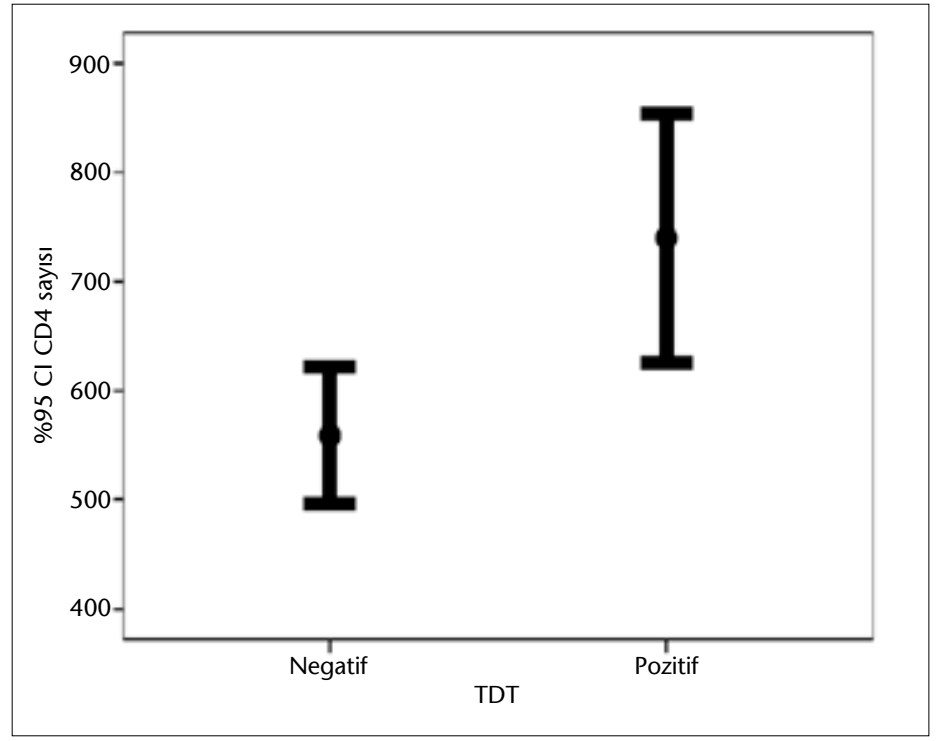

Şekil 4. Tüberkülin deri testi (TDT) ve CD4+ T lenfosit sayısının korelasyonu.

Tablo V. Tüberkülin Deri Testi ve CD4+ T Lenfosit Sayısının Korelasyonu

\begin{tabular}{lcccccccc}
\hline & & \multicolumn{7}{c}{ Ortalama Yüzdelik İçin \%95 Güven Aralığı } \\
\hline CD4+ T lenfosit sayısı & & Ort. & SD & Min & Maks & 25 & 50 & 75 \\
\hline TDT & Negatif & 558.9 & 271.8 & 495.9 & 621.8 & 358.8 & 521.0 & 775.5 \\
& Pozitif & 740.0 & 257.6 & 625.9 & 854.2 & 568.3 & 741.5 & 883.0 \\
\hline
\end{tabular}

TDT: Tüberkülin deri testi. 


\section{TARTIŞMA}

HIV ile enfekte kişilerde, LTBE tanısında TDT ve IGST testleri kullanılmakta olup henüz standart bir uygulama yoktur. TB'nin prevalansına ve ülkelerin gelişmişlik düzeyine göre farklı algoritmalar uygulanmaktadır ${ }^{4}$. Her iki testte de bellek $T$ hücre yanıtına bakılmaktadır $^{22}$. HIV ile enfekte kişilerde olduğu gibi bağışıklığı baskılanmış bireylerde, bu yanıtın azalması beklenmektedir. Nitekim çalışmamızda da hastaların yarısından fazlasında TDT 0 mm saptanmıştır. Markowitz ve arkadaşlarının ${ }^{23}$ yapmış olduğu, 1171 HIV ile enfekte ve 182 HIV ile enfekte olmayan kişinin dahil edildiği çalışmada TDT yanıtının CD4+ T lenfosit sayısıyla ilişkili olduğu gösterilmiştir. Literatürdeki benzer çalışmalarda, HIV ile enfekte kişilerde TDT yanıtının azaldığı ve bunun düşük CD4+ T lenfosit sayısıyla ilişkili olduğu gösterilmiştir ${ }^{24-26}$. Bizim çalışmamızda da CD4+ T lenfosit sayısı arttıkça, TDT ölçüm değerinin arttığı gözlenmiştir $(p=0.003)$. Bu durum, CD4+ T lenfosit sayısı düşük olan hastalarda, TDT'nin yalancı negatif sonuç verebileceğini düşündürmektedir. Yalancı negatif sonuçların engellenebilmesi için CD4+ T lenfosit sayısı düşük olan kişilerde, CD4+ T lenfosit sayısı yükseldiğinde TDT'nin tekrar edilmesi önerilmektedir ${ }^{27}$.

TDT'nin CD4+ T lenfosit sayısı ile olan ilişkisi yapılan çalışmalarda açık bir şekilde gösterilmişken, T-SPOT.TB testinin CD4+ T lenfosit sayısından etkilenip etkilenmediği konusu henüz açıklığa kavuşturulmamıştır. ELISPOT teknolojisinin IFN- $\gamma$ salgılayan T lenfositleri saptamada daha hassas bir yöntem olması ve ileri immün yetmezlik durumunda bile mitojen ile uyarılmış T lenfositlerin varlığını sürdürüyor olmasından dolayı genel olarak, T-SPOT.TB testin, CD4+ T lenfosit sayısından etkilenmediği düşünülmektedir ${ }^{17,28}$. Çalışmamızda da T-SPOT.TB test pozitifliği ile CD4+ T lenfosit sayısı arasında istatistiksel olarak anlamlı bir ilişki saptanmamıştır $(p=0.289)$. Bu bulgular ışığında, CD4+ T lenfosit sayısı düşük olan HIV ile enfekte hastalarda, LTBE tanısında T-SPOT.TB testinin tercih edilmesi önerilebilir. Fakat çalışmamıza, geçirilmiş TB'si olan hastalar ile daha önce LTBE nedeniyle tedavi almış hastalar dahil edilmemiştir. Çalışmamıza katılan hastaların özellikleri incelendiğinde, CD4+ T lenfosit sayısı 200 hücre $/ \mathrm{mm}^{3}$ ün altında olan hasta sayısının düşük olduğu görülmüştür. Bütün bu sebepler göz önüne alındığında, T-SPOT.TB testin yalancı negatiflik açısından değerlendirilebilmesi için, kanıtlanmış TB enfeksiyonu geçirmiş, çok sayıda HIV ile enfekte hastanın dahil edildiği çalışmaların yapılmasına ihtiyaç vardır.

LTBE tanısında TDT halen önemini korusa da, uygulamada çeşitli güçlükler yaşanmaktadır. Çalışmamıza katılan tüm hastalara LTBE ve riskleri hakkında bilgi verilmiş ve daha sonra telefonla aranarak kontrole çağrılmıştır. Buna rağmen çalışmaya katılan hastaların dördü, TDT'nin ölçümü için tekrar hastaneye başvurmamıştır. Aynı zamanda, çalışmamız tasarlanırken TDT'nin yalancı negatif sonuçlarının önüne geçilebilmesi için, TDT sonucu negatif saptanan hastalara booster TDT yapılması planlanmıştır. TDT negatif saptanan 74 hastanın hiçbiri, booster TDT yapılması için tekrar hastaneye başvurmamıştır. Hastalarla yapılan görüşmelerde, testin tekrarlanması için yeteri kadar zamanlarının olmadığı ifade edilmiştir. Pratik uygulamada yaşadığımız bu sorunlar, TDT'nin kullanımındaki güçlükleri göstermektedir. Bu nedenle LTBE tanısında, uyum ve/veya zaman problemi olan hastalarda TDT tercih edilmemelidir. 
TDT'nin uygulanmasındaki bu güçlüklere rağmen, IGST testlerde periferik kandan ölçüm yapıldığı için hastane ziyaretinin bir defa yapılması yeterli olacaktır. IGST testlerinin uygulamadaki kısıtılığı ise testlerin pahalı olması ve belirsiz sonuçlar verebilmesidir. Belirsiz sonuçların nedenleri arasında ileri yaş, immünsüpresyon ve teknik aksaklıklar gösterilmektedir. Beffa ve arkadaşlarının T-SPOT.TB testinin belirsiz sonuçlarının nedenlerini irdeledikleri çalışmada ${ }^{29}$ belirsiz sonuçlar, 75 yaş ve üzerindeki bireylerde daha sık ortaya çıkmıştır. Çalışmamıza katılan hiçbir hastada belirsiz sonuç saptanmasa da belirsiz sonuç vermesi halinde testin tekrarlanması gerekmektedir. Buna rağmen, IGST yalnız bir defa hastane ziyareti gerektirmesi nedeniyle TDT'ye üstündür.

Talati ve arkadaşlarının 336 HIV ile enfekte kişide yapmış oldukları çalışmada ${ }^{30}, 14$ hastada T-SPOT.TB test pozitifliği, yedi hastada ise TDT pozitifliği saptanmıştır. Sadece iki hastanın hem TDT'si hem de T-SPOT.TB testi pozitif saptanmış olup IGST ve TDT arasında düşük düzeyde bir uyum (Kappa= 0.16) olduğu gösterilmiştir. TDT pozitif/T-SPOT.TB negatif sonuçların, BCG aşısı varlığıyla ilişkili olduğu tespit edilmiştir. Overton ve arkadaşlarının yapmış olduğu derlemede ${ }^{31}$ ise, 1966 ve 2017 yılları arasında yapılmış olan 32 çalışma incelenmiştir. Bu derlemede IGST ve TDT'nin, LTBE tanısında karşılaştırıldığı 14'ü TB'nin düşük endemik olduğu, 12'si ise yüksek endemik olduğu ülkelerden olan 26 çalışma irdelenmiş̧ir. HIV ile enfekte 4425 kişinin LTBE açısından değerlendirildiği bu derlemede IGST ve TDT arasında genellikle düşük düzeyde bir uyum saptanmıştır. Çalışmamızda da T-SPOT.TB test ile TDT arasında orta düzeyde uyum saptanmıştır (Kappa=0.491). Literatürde yer alan çalışmalar incelendiğinde; TDT'nin, BCG aşısı ve atipik mikobakteri enfeksiyonu varlığında yalancı pozitif, düşük CD4+ T lenfosit sayısı varlığında ise yalancı negatif sonuç vermesinin uyumsuz sonuçlara neden olduğu görülmektedir ${ }^{9,16,22,28,30,32,33}$. Çalışmamızdaki pozitif sonuçlar incelendiğinde her iki grupta da 22 hastada pozitif sonuç saptanmış sadece 13 hastanın hem T-SPOT.TB test hem de TDT sonucunun pozitif olduğu görülmüştür. T-SPOT.TB test sonucu negatifken, TDT sonucu pozitif olan dokuz hasta saptanmıştır. Mevcut bulgular ışığında, bu dokuz hastadaki TDT pozitifliğinin yalancı pozitif sonuç olma ihtimali vardır. Hastaların özellikleri incelendiğinde hepsinin BCG aşılarının olduğu görülmüştür. Bu nedenle BCG aşısının, TDT ile çapraz reaksiyon vermiş olabileceği düşünülmektedir. Hastalara gereksiz yere LTBE tedavisinin verilmemesi için, TDT'nin yalancı pozitif sonuçlarının belirlenmesi gerekmektedir. Yalancı pozitifliğin önüne geçmek için BCG aşısı olan hastalarda, TDT sonucu değerlendirilirken aktif TB'si olan hastayla uzun süreli temas, uyuşturucu kullanımı gibi risk faktörlerinin de göz önünde bulundurulması gerekmektedir. Çalışmamıza katılan hastaların aktif TB'si olan hastayla temasına göre, testler arasında anlamlı fark saptanmamıştır. Ancak, hastalara TB hastasıyla karşılaşıp karşılaşmadıkları sorulduğu için, hastaların yakın çevresi dışındaki kişileri de düşünerek cevap vermiş olabilecekleri, ayrıca hastaların aktif TB'si olan kişileri değil geçirilmiş TB'si olan ya da pnömoni geçiren kişileri de bu kategori içinde saymış oldukları düşünülmektedir. Bu nedenle, hastalara aktif TB hastasıyla karşılaşıp karşılaşmadıkları sorulurken daha detaylı bir şekilde sorgulama yapılması gerekmektedir. Bütün bu faktörler göz önüne alındığında, risk faktörü olan, CD4+ T lenfosit sayısı yüksek ve BCG aşısı olmayan kişilerde LTBE tanısında TDT kullanılabileceği ancak risk faktörü belirsiz ve/veya BCG aşı kişilerde IGST'lerin kullanılmasının yalancı pozitif sonuçların önüne geçeceği görülmektedir. 
Sonuç olarak çalışmamız, TDT'nin CD4+ T lenfosit sayısından etkilendiğini ve TDT'ye hasta uyumunun güç olduğunu göstermiştir. Buna karşın, T-SPOT.TB testinin CD4+ T lenfosit sayısından etkilenmediği tespit edilmiştir. Bu yüzden HIV ile enfekte kişilerde, LTBE tanısında T-SPOT.TB testinin daha güvenilir olabileceği düşünülmüştür. T-SPOT.TB testi ile TDT arasındaki uyum orta düzeyde bulunmuştur. Testler arasındaki uyumsuzluğun başlıca nedeni olarak, TDT'nin yalancı negatif veya yalancı pozitif sonuçlarından kaynaklanmış olabileceği düşünülmüştür. Bu bulgular ışığında, özellikle CD4+ T lenfosit sayısı düşük olan HIV ile enfekte hastalarda, LTBE tanısının konulabilmesi için öncelikle T-SPOT.TB testinin tercih edilmesi gerektiği düşünülmüştür.

\section{ÇIKAR ÇATIŞMASI}

Yazarlar bu makale ile ilgili herhangi bir çıkar çatışması bildirmemişlerdir.

\section{KAYNAKLAR}

1. Masur H. Management of opportunistic infections associated with human immunodeficiency virus infection, pp: 1642-1665. In: Mandell GL, Bennet JE, Dolin R (eds), Mandell, Douglas and Bennett's Principles and Practice of Infectious Diseases. 2015, $8^{\text {th }}$ ed. Churcill Livingstone, Philadelphia.

2. World Health Organization. Global tuberculosis report 2016. http://www.who.int/tb/publications/global_ report/en/

3. Lawn SD, Wood R, Wilkonson RJ. Changing concepts of "latent tuberculosis infection" in patients living with HIV infection. Clin Dev Immunol 2011;2011:980594

4. Pai M, Menzies D, Baron EL (2016). Erişim tarihi: 23/12/2016 http://www.uptodate.com/contents/ diagnosis-of-latent-tuberculosis-infection-in-hiv-infectedpatients?source=search_result\&search=latent+tube rculosis+diagnosis\&selectedTitle=3 150

5. Yüce A, Şener A. Akciğer tüberkülozu, pp: 832-49. In: Wilke Topçu A, Söyletir G, Doğanay M (eds), Enfeksiyon Hastalıkları ve Mikrobiyolojisi. 2008, $3^{\text {rd }}$ ed. Nobel Tıp Kitabevleri, İstanbul.

6. Fauci AS, Lane HC. Human immunodeficiency virus disease: AIDS and related disorders, pp: 840-843. In: Kasper DL, Fauci AS (eds), Harrison's Infectious Diseases. 2010, $1^{\text {st }}$ ed. The McGraw-Hill Companies, New York.

7. T.C. Sağlık Bakanlığı Türkiye'de Verem Savaşı 2017 Raporu, Ankara, 2017

8. Huebner RE, Schein MF, Bass JB Jr. The tuberculin skin test. Clin Infect Dis 1993;17(6):968-75.

9. Rangaka MX, Wilkinson KA, Seldon R, Van Cutsem G, Meintjes GA, Morroni C, et al. Effect of HIV-1 infection on T-Cell-based and skin test detection of tuberculosis infection. Am J Respir Critic Care Med 2007; 175(5):514-20.

10. Menzies D, Pai M, Comstock G. Meta-analysis: new tests for diagnosis of latent tuberculosis infection: areas of uncertainty and recommendations for research. Ann Intern Med 2007;146(5):340-54.

11. Pai M, Riley LW, Colford JM. Interferon gamma assays in the immunodiagnosis of tuberculosis: a systematic review. Lancet Infect Dis 2004;4(12):761-76.

12. Öztürk N, Sürücüoğlu S, Özkütük N, Gazi H, Akçalı S, Köroğlu G, et al. Temaslılarda tüberküloz enfeksiyonunun tanısı için interferon-gama tam kan testi ile tüberkülin deri testinin karşılaştırılması. Mikrobiyol Bul 2007;41(2):193-202.

13. Cesur S, Hoca NT, Tarhan G, Çimen F, Ceyhan I, Annakkaya AN, Aslan T, et al. Tüberkülozlu hastalar, yakın temaslıları, sağlık çalışanları ve tüberküloz laboratuvarı personelinde Quantiferon-TB gold ve tüberkülin cilt testinin değerlendirilmesi. Mikrobiyol Bul 2010;44(4):553-60.

14. Pai M, Zwerling A, Menzies D. Systematic review: T-cell-based assays for the diagnosis of latent tuberculosis infection: an update. Ann Intern Med 2008;149(3):177-84. 
HIV ile Enfekte Hastalarda Latent Tüberküloz Enfeksiyonunu (LTBE) Belirlemede

Tüberkülin Deri Testi (TDT) ve T-SPOT.TB Testlerinin Karşılaştırılması

15. Mazurek GH, Jereb J, Vernon A, Lobue P, Goldberg S, Castro K. Updated guidelines for using Interferon Gamma Release Assays to detect Mycobacterium tuberculosis infection - United States. MMWR Recomm Rep 2010;59(RR-5):1-25.

16. Ramos JM, Robledano C, Masiá M, Belda S, Padilla S, Rodríguez JC, et al. Contribution of Interferon gamma release assays testing to the diagnosis of latent tuberculosis infection in HIV-infected patients: A comparison of QuantiFERON-TB Gold In Tube, T-SPOT.TB and tuberculin skin test. BMC Infect Dis 2012;12(1):169-79.

17. Leidl L, Mayanja-Kizza H, Sotgiu G, Baseke J, Ernst M, Hirsch C, et al. Relationship of immunodiagnostic assays for tuberculosis and numbers of circulating CD4+ T-cells in HIV infection. Eur Respir J 2010;35(3):619-26.

18. Stephan C, Wolf T, Goetsch U, Bellinger O, Nisius G, Oremek G, et al. Comparing QuantiFERON-tuberculosis gold, T-SPOT tuberculosis and tuberculin skin test in HIV-infected individuals from a low prevalence tuberculosis country. AIDS 2008;22(18):2471-9.

19. Elzi L, Steffen I, Furrer H, Fehr J, Cavassini M, Hirschel B, et al. Improved sensitivity of an interferon-gamma release assay (T-SPOT.TB) in combination with tuberculin skin test for the diagnosis of latent tuberculosis in the presence of HIV co-infection. BMC Infect Dis 2011;11(1):319-28.

20. Soysal A, Torun T, Efe S, Gencer H, Tahaoglu K, Bakir M. Evaluation of cut-off values of interferon-gammabased assays in the diagnosis of M. tuberculosis infection. The International Journal of Tuberculosis and Lung Disease 2008;12(1):50-6.

21. Kılınç O. Tüberkülin Deri Testi (TDT), Yorumu Ve Son Gelişmeler, 21. Yüzyılda Tüberküloz Sempozyumu ve II. Tüberküloz Laboratuvar Tanı Yöntemleri Kursu, 2012, Samsun, s: 203-7

22. Latorre I, Martinez-Lacasa X, Front R, Lacoma A, Puig J, Tural C, et al. IFN- $\gamma$ response on T-cell based assays in HIV infected patients for detection of tuberculosis infection. BMC Infect Dis 2010;10(1):348-56.

23. Markowitz N, Hansen NI, Wilcosky TC, Hopewell PC, Glassroth J, Kvale PA, et al. Tuberculin and anergy testing in HIV-seropositive and HIV-seronegative persons. Ann Intern Med 1993;119(3):185-93.

24. Chin DP, Osmond D, Page-Shafer K, Glassroth J, Rosen M J, Reichman L B, et al. Reliability of anergy skin testing in persons with HIV infection. The pulmonary complications of HIV infection study group. Am J Respir Crit Care Med 1996;153(6):1982-4.

25. Selwyn PA, Sckell BM, Alcabes P, Friedland GH, Klein RS, Schoenbaum EE. High risk of active tuberculosis in HIV-infected drug users with cutaneous anergy. JAMA 1992;268(4):504-9.

26. Caiaffa WT, Graham NMH, Galai N, Rizzo R T, Nelson K E, Vlahov D. Instability of delayed-type hypersensitivity skin test anergy in human immunodeficiency virus infection. Arch Intern Med 1995;155(19):2111-7.

27. T.C. Sağlık Bakanlığı Tüberküloz Tanı Tedavi Rehberi, Ankara, 2011.

28. Dheda K, Lalvani A, Miller RF, Scott G, Booth H, Johnson MA, et al. Performance of a T-cell-based diagnostic test for tuberculosis infection in HIV-infected individuals is independent of CD4 cell count. AIDS 2005;19(17):2038-41.

29. Beffa P, Zellweger A, Janssens JP, Wrighton-Smith P, Zellweger JP. Indeterminate test results of T-SPOT.TB performed under routine field conditions. Eur Respir J 2008;31(4):842-6.

30. Talati NJ, Seybold U, Humphrey B, Aina A, Tapia J, Weinfurter P, et al. Poor concordance between interferongamma release assays and tuberculin skin tests in diagnosis of latent tuberculosis infection among HIVinfected individuals. BMC Infect Dis 2009;9(1):15-24.

31. Overton K, Varma R, Post JJ. Comparison of interferon- $\gamma$ release assays and the tuberculin skin test for diagnosis of tuberculosis in human immunodeficiency virus: a systematic review. Tuberc Respir Dis (Seoul) 2018;81(1):59-72.

32. Richeldi L, Losi M, D’Amico R, Luppi M, Ferrari A, Mussini C, et al. Performance of tests for latent tuberculosis in different groups of immunocompromised patients. Chest 2009;136(1):198-204.

33. Mandalakas AM, Hesseling AC, Chegou NN, Kirchner HL, Zhu X, Marais BJ, et al. High level of discordant IGRA results in HIV infected adults and children. Int J Tuberc Lung Dis 2008;12(4):417-23. 